\title{
Hygienebeauftragter Arzt - Blended Learning Kurs auch für Radiologen
}

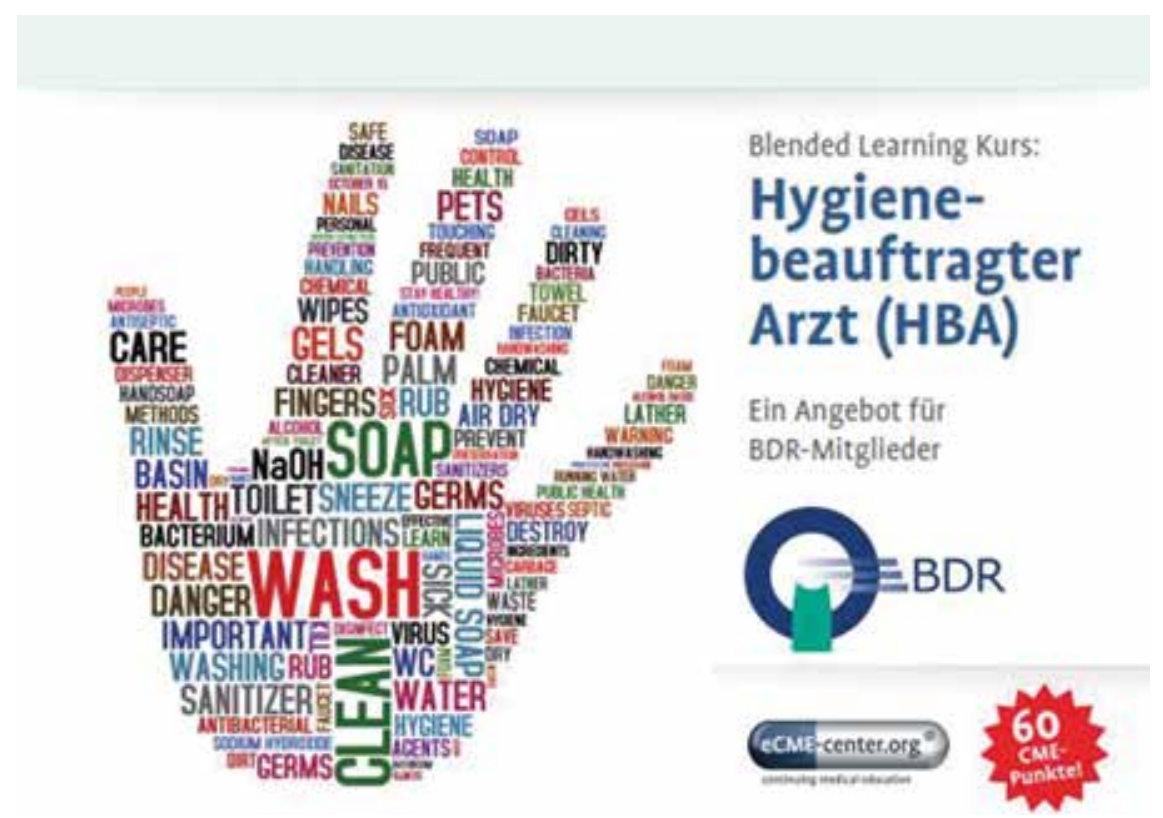

Bei diesem Kursanagebot kooperieren wir mit dem Berufsverband der Chirurgen. Deren BDC|Akademie hat gemeinsam mit renommierten Krankenhaushygienikern ein kompaktes Blended-Learning-Angebot zur Erlangung der Zusatzqualifikation „Hygienebeauftragter Arzt“ entwickelt.

Im Gegensatz zu den üblichen 40-stündigen Präsenzkursen zeichnet sich dieser Kurs durch einen kombinierten Ansatz aus E-Learning, Abschlusskolloquium sowie einem kontinuierlichen Wissens-Update aus. Dieses Konzept kommt dem engen Zeitbudget von Ärzten entgegen und lässt sich nahtlos in den Klinik- und Praxisalltag integrieren.

Für die E-Learning-Module existiert eine App für Apple- und Android-Smartphones und Tablets. Damit sind alle Lernmodule auch auf den gängigen mobilen Endgeräten verfügbar und können unterwegs ohne Internetzugang bearbeitet werden. Nach erfolgreichem Abschluss des Kurses können Sie mit der App oder im Internet auch weiterhin auf die Kursinhalte als Re- ferenz und Nachschlagewerk zugreifen. Über die Apps auch offline.

Die nächsten Termine für das Abschlusskolloquium in 2017 - Kursort Berlin - sind

- 03.-04. Februar 2017

05.-06. Mai 2017

- 13.-14.Oktober 2017

Den Kursflyer können Sie gern bei uns anfordern: presse@radiologenverband.de

\section{Kommentierung „Kurs zum hygienebeauftragten Arzt ${ }^{\text {“* }}$ $\nabla$}

Die Funktion des hygienebeauftragten Arztes wird von den Geschäftsführungen der Kliniken in aller Regel dem Chefarzt der jeweiligen Abteilung übertragen. Die hierfür nötigen Kenntnisse sind umfangreich und werden üblicherweise in einem Präsenzkurs über eine Woche vermittelt und erworben.

Der Berufsverband der Deutschen Chirurgen (BDC) hat jetzt eine strukturierte,

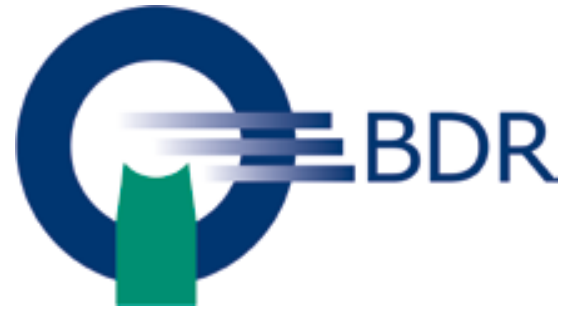

curriculare Fortbildung gemäß den Vorgaben der Bundesärztekammer nach dem Blended-Learning-Konzept entwickelt. Dabei erwirbt der Teilnehmer durch interaktives Lernen auf einer Internetplattform den Großteil des Wissens zu selbst gewählter Zeit und in selbst gewählten zeitlichen und thematischen Abschnitten. Zum Abschluss eines Kapitels hat man die Möglichkeit sein Wissen anhand von Auswahlfragen zu überprüfen. Nach Abschluss aller Themenkapitel schließt ein obligater Test mit Auswahlfragen den Interaktivteil ab. Das Bestehen dieses Testes ist dann Voraussetzung für die Teilnahme am 2-tägigen Präsenzteil in Berlin an dessen Ende das Abschlusskolloquium steht.

Die neue Lernplattform hat den Vorteil der selbstständigen Zeiteinteilung bis zur Teilnahme am Präsenzteil. Auch stehen die Lernunterlagen beliebig lange zum Nachschlagen zur Verfügung. Das Programm ist damit eine gute Alternative zum zeitlich sehr aufwändigen Präsenzkurs. Und im Angebot des BDR, der als Kooperationspartner des BDC auftritt, ist er zudem deutlich preislich reduziert.

\section{Prof. Hermann Helmberger} München

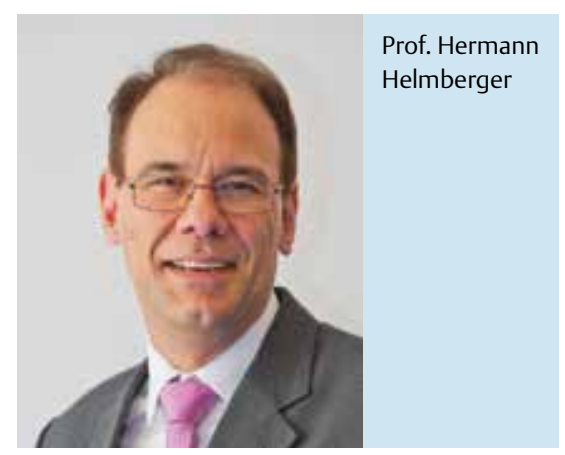

